\title{
Diagnosis, Management and Recovery of COVID 19: a Case Report in Bangladesh
}

\author{
Lutfa Akther ${ }^{1}$, Shaila Shahnewaz ${ }^{2}$, Dilruba Ferdous ${ }^{1}$, and Md. Moyen Uddin PK ${ }^{3}$ \\ ${ }^{1}$ Dhaka Medical College and Hospital \\ ${ }^{2}$ Affiliation not available \\ ${ }^{3}$ University of Rajshahi
}

July 24, 2020

\begin{abstract}
A 30-year-old man, who had no travel history to COVID-19 prone areas whereas he had the characteristics signs and symptoms of COVID-19. Chest X-ray and rRT-PCR revealed his confirmed COVID-19. This study recommends the early identification and management of COVID-19.
\end{abstract}

\section{INTRODUCTION}

COVID-19 (Coronavirus disease), caused by severe acute respiratory coronavirus 2 syndrome (SARS-CoV2), was first identified in Wuhan, China, in December 2019(1). The World Health Organization declared a public health emergency of international concern regarding this global outbreak of pneumonia on 30 January 2020. Globally, as of 9:37am CEST, 30 May 2020, there have been 5,796,257 confirmed cases of COVID-19, including 362,483deaths, reported to $\mathrm{WHO}(2)$. In Bangladesh, as of 4 June 2020, there have been about 52000 confirmed cases of COVID-19 with about 700 deaths. The virus COVID-19 is primarily transmitted between humans through respiratory droplets and contact routes. Analysis of 75,465 COVID-19 cases in China has not reported airborne transmission(3-5). Early moderate signs occurred during the course of the disease offer a chance to early detect COVID-19. Fast identification and accurate treatment have been critical to avoiding the spread of infection $(6,7)$. At present, transcription polymerase chain reaction (RT-PCR) and real-time RT-PCR (rRT-PCR) are used to detect gene expressions of SARS CoV-2. There are three genes expression of SARS CoV-2 such as the RNA-dependent RNA polymerase (RdRp)/helicase (Hel), spike (S), and nucleocapsid $(\mathrm{N})$ genes $(8,9)$. In Bangladesh, rRT-PCR is used to detect early COVID-19. After a week, point-of-care test kits for $\mathrm{Ag}$ and $\mathrm{Ab}$ is used to measure the protective level of plasma antibodies ( IgM and IgG). In this study, we reported COVID-19 case of man who had no travel history to COVID-19 prone areas whereas he had the characteristics signs and symptoms of COVID-19. Chest X-ray and rRT-PCR revealed his confirmed COVID-19.

\section{CASE HISTORY AND EXAMINATION}

On April 13 at 11:30 AM, 2020, 30-year-old man came to a tertiary hospital, Dhaka, Bangladesh with significant signs and symptoms of COVID 19 and he had dry cough, muscle pain, fever, headache and shortness of breath. On the spot, he admitted and recorded the vital signs of COVID 19. The vital signs are shown in table 1 . He had no history of direct contact of COVID 19 positive patients. On $14^{\text {th }}$ April at 10:15 PM, he was confirmed COVID 19 using RT-PCR nasal swab test. The result of RNA detection of SARS CoV-2 was positive (Table 2). Same at 00:45 AM, h was moved to an isolated cabin and received supportive treatment.The next day on $15^{\text {th }}$ April at 9:45 PM, he had got complete blood counts and results did not reveal leukocytopenia. Chest X-ray, on the other hand, showed ground-glass darkness in the center and lower 
right of the lung (Table 2). The chest X-ray examination revealed that he was strongly suspected of having COVID-19. On 16 April at 10:30 a.m., he was inspired to re-test two samples (nasal and throat) for RT-PCR and the findings were positive. Same at 11:35 PM, he was treated with antibiotics (azithromycin ${ }^{500}$ ), $\mathrm{O}_{2}$ inhilation, intravenous fluid, paracetamol ${ }^{500}$, Montelukast ${ }^{10}$, and Fexofenadine ${ }^{120}$. After 3 days of treatment $\left(19^{\text {th }}\right.$ April, 2020), his fever and breathing difficulty improved and his condition was stable for 72 hours. On $23^{\text {rd }}$ and $24^{\text {th }}$ April, he was tested for SARS CoV-2 RNA with two subsequent throat swab samples respectively. The results of RT-PCR were negative (Table 2). On $25^{\text {th }}$ April at 11:25 AM, he was discharged and recommemded to follow the rule-and-regulations of home quarantine for the next 14 days. On $1^{\text {st }}$ May 2020, during his follow-up period, he was recommended to monitor the blood IgM and IgG against SARS $\mathrm{CoV}-2$ antigen. Antibodies (IgM and IgG) were measured using point-of-care test and results showed the protective level of IgG (Table 2). The shapshot of COVID-19 is shown in figure 1.

\section{DISCUSSION}

Severe illness of COVID-19 begins after 7 days (approx.) of onset of symptoms. The most common symptoms of COVID-19 are fever, cough, tiredness, dyspnea, and diarrhea. (10, 11). Severe COVID-19 dyspnea triggers progressive development of respiratory failure, followed by severe hypoxemia. In fact, lymphopenia is normal to the majority of severe COVID-19(12,13). The analysis of COVID-19 is made using real-time polymerase chain reaction methods, partial or complete viral genome sequencing, and plasma antibody level measurements. Early diagnosis of SARS CoV-2 is made by collecting, processing, and analyzing respiratory samples such as nasopharyngeal aspirate, combined (nasal and oral) swab samples, sputum, tracheal lavage fluid, or bronchoalveolar lavage fluid(14). SARS CoV-2 RNA is isolated from respiratory samples and measured utilizing rRT-PCR using the process of placing probes. COVID-19 is verified by viral RNA being found in the samples obtained(15). Within a week of the emergence of COVID-19 symtomps, plasma IgM and IgG tests are necessary to allow the infection to be easily detected. It showed that a patient had the safe amount of IgG within 14 days. Through the point-of-care test, it can identify the existence of serum antibodies within 15 minutes and can determine the level of the infection(16). CT findings are significant both for diagnosis and follow-up. To present, there has been no proof of successful treament for COVID19. Antiviral medications and respiratory treatment are the primary medication used to cure the disorder. In addition, while several therapies have been suggested, quarantine is the only method that seems to be successful.

\section{CONCLUSION}

The most critical feature of treatment in this case study is close observation of the respiratory condition of the patient in order to assess if a ventilator is necessary. The patient is recommended to follow two weeks home quarantine (14d) with proper food management and two weeks allows them adequate opportunity to learn whether or not they can get infected and spread to other citizens.

\section{FUNDING}

This research did not receive any specific grant.

\section{ACKNOWLEDGMENT}

The patient received informed consent to the release of this case study.

\section{CONFLICT-OF-INTEREST}

The authors declared no conflict of interest.

\section{AUTHOR CONTRIBUTION}

Lutfa Akther, Shaila Sharmin Shahnewaz, and Dilruba Ferdous: They were involved in data collection and reviewed the manuscript. Md. Moyen Uddin Pk.: He did data analysis and wrote the manuscript.

\section{References}


1. Singhal T. A Review of Coronavirus Disease-2019 (COVID-19). Indian J Pediatr. 2020;87(4):281-6.

2. WHO. WHO Coronavirus Disease (COVID-19) Dashboard 2020 [Available from: https://covid19.who.int/.

3. Jiaye L, Xuejiao L, Shen Q, Jing Y, Fuxiang W, Yingxia L, et al. Community Transmission of Severe Acute Respiratory Syndrome Coronavirus 2, Shenzhen, China, 2020. Emerging Infectious Disease journal. 2020;26(6):1320.

4. Li Q, Guan X, Wu P, Wang X, Zhou L, Tong Y, et al. Early Transmission Dynamics in Wuhan, China, of Novel Coronavirus-Infected Pneumonia. New England Journal of Medicine. 2020;382(13):1199-207.

5. Burke RM, Midgley CM, Dratch A, Fenstersheib M, Haupt T, Holshue M, et al. Active Monitoring of Persons Exposed to Patients with Confirmed COVID-19 - United States, January-February 2020. MMWR Morb Mortal Wkly Rep [Internet]. 2020; 69(9):245-9.

6. Yi Y, Lagniton PNP, Ye S, Li E, Xu R-H. COVID-19: what has been learned and to be learned about the novel coronavirus disease. Int J Biol Sci. 2020;16(10):1753-66.

7. Zhai P, Ding Y, Wu X, Long J, Zhong Y, Li Y. The epidemiology, diagnosis and treatment of COVID-19. Int J Antimicrob Agents. 2020;55(5):105955-.

8. Bhadra S, Jiang YS, Kumar MR, Johnson RF, Hensley LE, Ellington AD. Real-Time Sequence-Validated Loop-Mediated Isothermal Amplification Assays for Detection of Middle East Respiratory Syndrome Coronavirus (MERS-CoV). PLOS ONE. 2015;10(4):e0123126.

9. Corman VM, Eckerle I Fau - Bleicker T, Bleicker T Fau - Zaki A, Zaki A Fau - Landt O, Landt O Fau - Eschbach-Bludau M, Eschbach-Bludau M Fau - van Boheemen S, et al. Detection of a novel human coronavirus by real-time reverse-transcription polymerase chain reaction. LID - 20285 [pii]. (1560-7917 (Electronic)).

10. Richardson S, Hirsch JS, Narasimhan M, Crawford JM, McGinn T, Davidson KW, et al. Presenting Characteristics, Comorbidities, and Outcomes Among 5700 Patients Hospitalized With COVID-19 in the New York City Area. JAMA. 2020;323(20):2052-9.

11. Huang C, Wang Y, Li X, Ren L, Zhao J, Hu Y, et al. Clinical features of patients infected with 2019 novel coronavirus in Wuhan, China. (1474-547X (Electronic)).

12. Ranieri Vm Fau - Rubenfeld GD, Rubenfeld Gd Fau - Thompson BT, Thompson Bt Fau - Ferguson ND, Ferguson Nd Fau - Caldwell E, Caldwell E Fau - Fan E, Fan E Fau - Camporota L, et al. Acute respiratory distress syndrome: the Berlin Definition. (1538-3598 (Electronic)).

13. Lima CMAdO. Information about the new coronavirus disease (COVID-19). Radiol Bras. 2020;53(2):VVI.

14. Jacofsky D, Jacofsky EM, Jacofsky M. Understanding Antibody Testing for COVID-19. J Arthroplasty. 2020:S0883-5403(20)30442-3.

15. Udugama B, Kadhiresan P, Kozlowski HN, Malekjahani A, Osborne M, Li VYC, et al. Diagnosing COVID-19: The Disease and Tools for Detection. ACS Nano. 2020;14(4):3822-35.

16. Zhou P, Yang XL, Wang XG, Hu B, Zhang L, Zhang W, et al. A pneumonia outbreak associated with a new coronavirus of probable bat origin. (1476-4687 (Electronic)).

\section{List of figure legends}

Figure 1. The shapshot of COVID-19 of a 30-year-old man. 


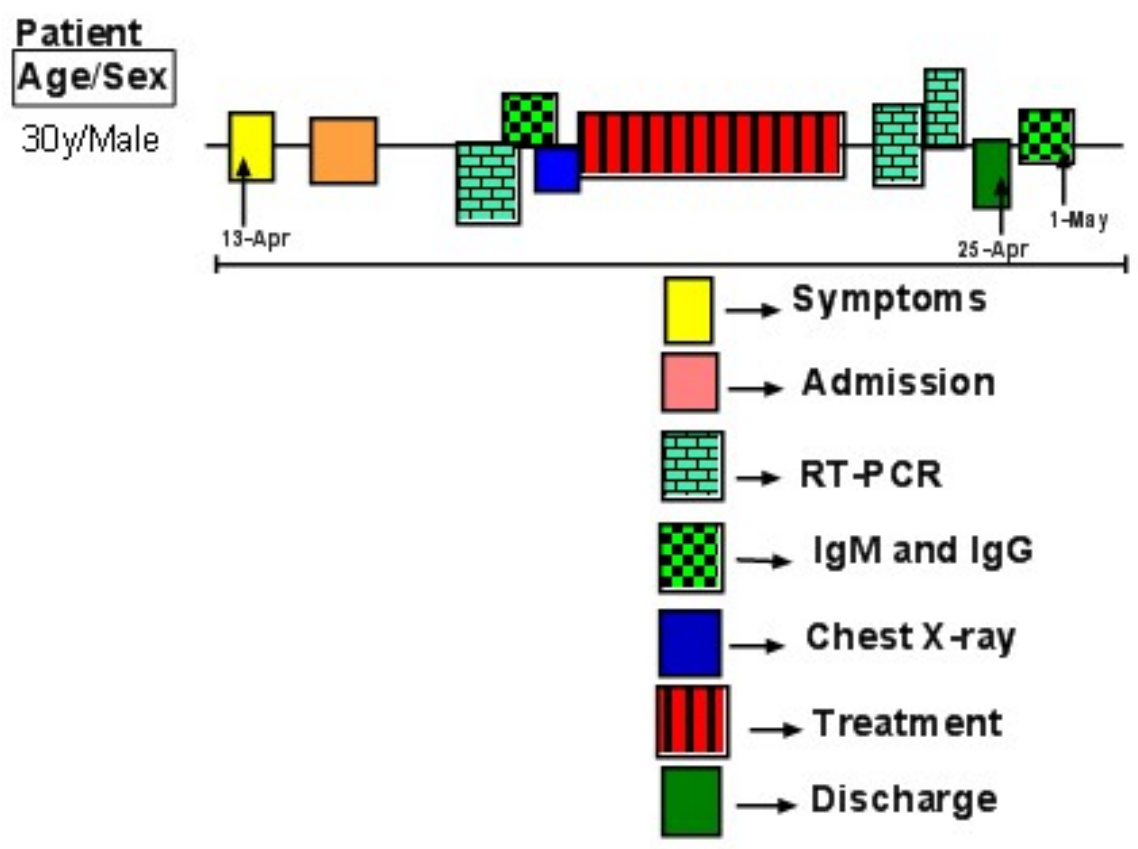

